\title{
O CURRÍCULO E A NOVA RACIONALIDADE DA SOCIEDADE DO CONHECIMENTO: EFEITOS NA PRÁTICA DOCENTE
}

\author{
Laura Cristina Vieira Pizzi ${ }^{1}$ \\ Roseane Maria de Amorim ${ }^{2}$
}

\section{Resumo}

O objetivo deste artigo é destacar alguns pontos relativos à sociedade do conhecimento $e$ como as questões que circundam esse tema produzem efeitos no currículo escolar e na formação das pessoas. Partimos do pressuposto de que as políticas curriculares no Brasil tomam o currículo como lócus de construção de uma nova racionalidade, que tende a colocar em segundo plano o papel dos saberes escolares, priorizando a obtenção de informações e o desenvolvimento de determinadas competências.

Palavras-chave: currículo, sociedade do conhecimento, vontade de aprender, racionalidade, saberes escolares.

\section{Resumen}

El propósito de este artículo es destacar algunos puntos en relación con la sociedad del conocimiento y cómo las cuestiones relacionadas con este tema producen efectos en el currículo escolar y en la formación de las personas. Partimos de la suposición de que las políticas curriculares en Brasil tienen el currículo como locus de construcción de una nueva racionalidad, que tiende a poner en segundo plano el papel de los conocimientos escolares, dando prioridad a la adquisición de información y al desarrollo de ciertas habilidades.

Palabras clave: currículo, sociedad del conocimiento, disposición para aprender, racionalidad, saberes escolares.

\section{Introdução}

Este artigo se propõe a discutir o lugar do currículo escolar no que se refere à lógica da racionalidade das competências e as suas implicações no tocante à

\footnotetext{
${ }^{1}$ Professora do Centro de Educação da Universidade Federal de Alagoas e coordenadora do grupo de pesquisa Atividade Docente e Subjetividade. E-mail: lcvpizzi@hotmail.com

${ }^{2}$ Professora do Centro de Educação da Universidade Federal de Alagoas e membro do grupo de Pesquisa Atividade Docente e Subjetividade. E-mail: roseane.mda@hotmail.com

PIZZI, Laura Cristina Vieira; AMORIM, Roseane Maria de. O currículo e a nova racionalidade da sociedade do conhecimento: efeitos na prática docente. Revista SulAmericana de Filosofia e Educação. Número 23: nov/2014-abr/2014, p. 107-130.
} 
prática docente. Os educadores, muitas vezes alheios aos debates referentes à problemática curricular, deixam de rever determinadas posturas e repensar os significados dos conteúdos trabalhados em sala de aula, bem como ter uma visão mais ampla do currículo, envolvendo as práticas sociais e as diversas formas de abordá-lo.

Por outro lado, o cotidiano de sala de aula, principalmente no Brasil, com suas inúmeras dificuldades, tem levado vários educadores a questionar os problemas vividos no mundo contemporâneo para ensinar crianças, jovens $e$ adultos em contextos tão diferentes das décadas de 1970 e 1980, por exemplo.

O que será que tem acontecido com a nossa sociedade, que cada vez mais a relação entre professor e estudante apresenta-se tão desgastada? Por que na maioria das vezes os nossos jovens não têm tido interesse pelo que é ensinado nas escolas ou mesmo na universidade? Existem caminhos que possam possibilitar realmente mudanças nas relações entre professores e educandos, que favoreçam uma educação que seja mais sedutora e envolvente para os estudantes, em todos os níveis e modalidades de ensino? Estas não são questões novas, entretanto. Grande parte dos desafios reside na possibilidade de analisar o complexo momento em que vivemos. Neste trabalho, tentaremos fazer essa análise, colocando o currículo no centro do debate da arena educacional.

É importante frisar que não apenas sabemos - mas somos também parceiras solidárias - que, devido à precariedade do trabalho docente e às condições de vida dos educandos e professores, a educação escolarizada tem limites que afetam a qualidade do seu trabalho, que estão fora das possibilidades individuais de resolução.

É, portanto, a partir das teorias curriculares, que olhamos para a prática docente enfatizando o processo de ensino e aprendizagem como locus fundamental do trabalho educativo. O que fazemos no cotidiano em sala de aula, quando nos toca educar as pessoas, é efetivar as práticas que irão ter efeitos na formação e na construção das identidades desses seres humanos. O nosso trabalho, de um jeito ou de outro, tem implicações sobre a formação das pessoas, embora nem sempre percebamos os resultados no momento em que atuamos. 
Perceber essa sutileza da dimensão curricular também tem sido um dos grandes desafios contemporâneos para os docentes.

\section{A racionalidade da sociedade do conhecimento e o lugar do conhecimento}

Hoje, mais do que antes, os educadores encontram-se permeados por muitos desafios e demandas. Se, por um lado, no nosso país os docentes ainda continuam sendo desvalorizados, com baixos salários e condições inadequadas de trabalho, por outro, a sociedade em geral, os movimentos sociais, os governos e os próprios estudantes têm exigido desses profissionais um conjunto de competências e habilidades jamais requisitado em outros tempos.

A escola e, por conseguinte, seus profissionais estão sendo acusados de não estarem ensinando e não estarem conseguindo promover a aprendizagem dos estudantes, formando pessoas sem o conhecimento necessário para viver no mundo globalizado (MOREIRA, 2005; MOREIRA; SILVA, 2006).

Os docentes, por sua vez, argumentam sobre a dificuldade de trabalhar com os estudantes da atualidade, da ausência da família na educação dos seus filhos, das políticas educacionais que têm se preocupado muito mais com dados estatísticos de aprovação dos estudantes do que com sua efetiva aprendizagem $e$ de não encontrarem uma solução para os problemas relacionados às condições de trabalho. Diante de tantas questões, os professores parecem confusos, desafiados a respeito de quais rumos devem tomar e quais seriam as possibilidades reais para resolver situações aparentemente novas, ainda que parcialmente. Por outro lado, os professores encontram-se sobrecarregados e sentindo-se responsáveis pelos persistentes resultados negativos das avaliações nacionais. Além disso, eles se encontram em uma encruzilhada que, dentre outras coisas, tende a provocar desencantos e adoecimento.

Diante dessa realidade, a reflexão sobre o currículo tem sido central para o entendimento das questões que inquietam os educadores. Ainda que o currículo não deva ser pensado como a solução de todos os problemas, compreendemos que a questão curricular é um dos elementos essenciais para apontar algumas 
possibilidades e saídas que os educadores possam trilhar e os desafios colocados pelas demandas sociais e econômicas atuais.

Principalmente, a partir da década de 1980, têm sido correntes as discussóes a respeito das políticas educacionais que envolvem as ações governamentais, as leis, as propostas curriculares e/ou as práticas curriculares vividas no âmbito escolar, além do debate recorrente sobre o que se deve ensinar. Ainda que, no cotidiano escolar atual, o currículo possa ser visto como uma listagem de conteúdos, ou programa de uma determinada disciplina, ou ainda como a distribuição das matérias em uma grade curricular, nos últimos anos ele tem sido tomado como objeto de estudo por diversas fontes, e o seu significado vem se ampliando e se tornado complexo.

Amorim (2011) afirma que, ao analisar a palavra currículo, encontramos um rol de definições. Historicamente, foi a partir da concepção de currículo estabelecida por Bobbitt em 1918, que essa área do conhecimento emergiu no mundo acadêmico. A visão desse autor sobre o currículo reside, de certo modo, em uma visão técnica voltada para um conjunto de experiências vividas pelos estudantes ao longo de sua trajetória escolar. Nessa perspectiva, o currículo é visto desvinculado dos problemas sociais, econômicos e políticos que envolvem a sociedade, ou, quando o é, tende a estar estreitamente vinculado com o mundo produtivo ${ }^{3}$.

Consolidando o trabalho de Bobbitt, o livro de Ralph Tyler, traduzido aqui no Brasil como Princípios Básicos de Currículo e Ensino, assume, também, uma perspectiva estritamente técnica. Preocupado com quais seriam os objetivos educacionais e quais as experiências que as escolas deveriam promover aos educandos, para que o ensino se tornasse eficaz, Tyler delimita o foco do referido estudo. Nessa perspectiva, a eficiência é a referência para o currículo. Com base na

\footnotetext{
${ }^{3}$ Segundo Silva (2000), Moreira (2002), Pacheco (2005) e Amorim (2004), a emergência do currículo como campo de estudo está estreitamente ligada ao estudioso norte-americano Bobbit que, em 1918, escreveu The curricullum. Os princípios da Administração de Taylor que trataram do aumento da produtividade, através de tarefas fragmentadas, segundo padrões rigorosos, e o estudo dos trabalhadores deveriam guiar o mundo da escola, isto é, a educação deveria ser tão eficiente quanto o ambiente empresarial. Em 1949, Ralph Tyler, com o livro Basic principles of currícullum na instrucion, publicado nos Estados Unidos, iria consolidar os estudos de Bobbit.
} 
racionalidade técnica, a escola deveria ser tão eficaz quanto o mundo da indústria, para que possa atingir os resultados desejados.

Nesse sentido, a preocupação principal não seria com a formação ampla dos sujeitos e, sim, a sua mera preparação técnica para ingressar no mercado de trabalho. Enfim, o currículo é visto como um programa de ensino, isto é, um conjunto de conteúdos que devem fazer parte das disciplinas, visando moldar o sujeito à estrutura capitalista.

Analisando o que Bobbitt levantou no início do século XX e o contexto na sala de aula da realidade brasileira, seja na educação básica ou no ensino superior, questionamos: Até que ponto essa concepção de currículo foi superada? Até que ponto o trabalho docente, devido aos inúmeros fatores subjacentes, tem rompido com essa perspectiva meramente técnica, voltada para a formação de cidadãos produtivos e capazes de inserir-se no mercado de trabalho?

Nessa perspectiva, o currículo não abrange as questões de ordem social e, em consequência, não questiona as desigualdades sociais provocadas pelas diferenças geradas no âmbito da cultura, a exemplo das desigualdades com motivação nos elementos das identidades diversas, tais como: identidade do jovem, da mulher, do sertanejo, do imigrante, do negro etc.

A partir dos anos 90, com as mudanças promovidas no campo da política públicas, com forte marca neoliberal, uma nova racionalidade emerge na educação, impregnando os discursos sobre o currículo, notadamente nos Parâmetros Curriculares Nacionais (PCN). Segundo Garcia (2010),

As reformas atuais são práticas globais que visam a mudanças nos padrões de regulação social e nos regimes éticos que capacitam os sujeitos para as relações sociais. As reformas incorporam sistemas de razão e conhecimento como práticas de inclusão e exclusão que produzem posições de sujeito, sistemas de classificação e distinções, que formam o horizonte ético do indivíduo consigo mesmo e com os outros (GARCIA, 2010, p. 446).

Como esclarece a autora (2010), o termo "racionalidade" está relacionado à introdução de uma certa ordem na forma de ordenar coisas visando sua eficácia. As racionalidades políticas criam laços entre razão, poder político e estruturas do 
Estado. Esses sistemas de razão e conhecimento produzidos pelas políticas educacionais neoliberais visam alinhar as ações dos sujeitos às demandas de governamentais, através de normas, discursos, tecnologias e inúmeras estratégias que favoreçam a sua eficácia com custos mínimos. Para o currículo escolar, os efeitos dessa nova racionalidade política produziu um novo modo de pensar os saberes, que passaram a um plano secundário, dando lugar às competências ${ }^{4} \mathrm{com}$ ênfase nos aspectos cognitivos, comportamentais e operacionais da aprendizagem, especialmente a habilidade de aprender a aprender, que vem ocupando um lugar de destaque nas retóricas da denominada sociedade do conhecimento contemporânea.

O currículo por competências vem se configurando numa potente tecnologia para formar determinados sujeitos para atuar e viver no contexto econômico $e$ social contemporâneo. Estamos definindo aqui as tecnologias em conformidade com a concepção de Rose (2001). Para o autor, as tecnologias seriam

um conjunto estruturado por uma racionalidade prática $e$ governado por um objetivo mais ou menos consciente. As tecnologias humanas são montagens híbridas de saberes, instrumentos, pessoas, sistemas de julgamento, edifícios $e$ espaços, orientados, no nível programático, por certos pressupostos e objetivos sobre os seres humanos (ROSE, 2001, p. 38).

O objetivo mais importante das tecnologias, ou mais acuradamente denominadas por Rose como "tecnologias humanas", é o enquadramento das condutas dos cidadãos dentro de uma lógica que se pretende dominante. Em outras palavras, visa a formação de experiências e subjetividades fortemente alinhadas aos interesses do mercado e a uma moral conservadora.

\section{A "vontade de saber" e a "vontade de aprender": a força dessas lógicas sociais na sociedade e na escola}

\footnotetext{
${ }^{4}$ Ver COSTA (2005).
} 
Nosso ponto de partida para essa discussão será o currículo escolar em sua dimensão social, ou seja, envolvendo saberes e práticas pedagógicas e culturais e as implicações da nova racionalidade política neoliberal presente nos discursos da denominada sociedade do conhecimento contemporânea, procurando destacar o papel ambíguo dos saberes curriculares nessa lógica.

Segundo Foucault (1996), entre os séculos XVI e XVII, observamos o surgimento de uma vontade de saber que prescreveria os saberes a uma dimensão técnica, verificável e útil, sobretudo na Inglaterra, os quais designamos como conhecimento científico, instaurando uma vontade de verdade apoiada em um suporte institucional, dentre as quais se situa a Pedagogia, e, podemos citar mais diretamente, o currículo escolar. Essa novo modelo ganha corpo através das formas como esse conjunto de saberes e práticas é valorizado, distribuído, repartido e atribuído na sociedade, constituindo-se como um sistema potente de exclusão e inclusão. A ciência passou a ser um discurso de verdade e que alimenta um desejo de saber, que tem sido a marca mais significativa da modernidade. A vontade de verdade e a vontade de saber estavam irremediavelmente implicadas e permanentemente alimentadas pelo desejo e pelo poder. No plano institucional se originaram em particular as áreas do conhecimento $e$ as disciplinas científicas, com pertenças doutrinárias fortemente controladas discursivamente. $\mathrm{O}$ motor do progresso industrial tem sido, desde a primeira revolução industrial, atribuído ao desenvolvimento de conhecimentos científicos e tecnológicos. A escola, particularmente a de nível superior, é a instituição produtora e reprodutora desses saberes (APPLE, 1989).

Recentemente, assistimos o surgimento de um novo discurso, o discurso da "vontade de conhecer", que parece alinhar-se à "vontade de saber" revitalizando a discussão. A sociedade do conhecimento vem se apresentando como uma verdadeira revolução no mundo atual, no âmbito do trabalho e nos modos de fazer a educação, cujos discursos e orientações doutrinárias predominantes passaram a ser o da vontade de aprender.

Todo o desenvolvimento econômico, pressuposto como promotor do desenvolvimento e do bem-estar humano se baseia no conhecimento e na 
capacidade de uma sociedade em produzir conhecimento. Não há novidade alguma nessa afirmação, uma vez que a própria modernidade se alicerça e sustenta a sua razão de ser no desenvolvimento científico e tecnológico. No entanto, como afirmam David e Foray (2003), "Economia Baseada no Conhecimento" ${ }^{5}$ é um termo recente e o que muda, em relação aos modelos de desenvolvimento anteriores, é a velocidade com que o conhecimento, esse capital imaterial, é produzido, acumulado e, em muitos casos, depreciado, em termos de valor econômico, cedendo lugar para os novos. Segundo os autores, o capital imaterial pode ser compreendido em duas categorias: por um lado, como um investimento voltado para a produção e a disseminação de conhecimento (treinamento, educação, pesquisa e desenvolvimento, informação etc.); por outro, como um investimento orientado para sustentar o estado físico do capital humano (cuidado $e$ saúde). No entanto, são os conhecimentos científicos e tecnológicos que detém um papel estratégico nesse panorama, pelo poder de produzir novos bens e novas estratégias, que teriam o potencial de facilitar e melhorar a vida das pessoas.

$\mathrm{E}$, mais uma vez, se produz uma visão de que o bem-estar dos seres humanos só pode ser atingido em um contexto de elevado desenvolvimento tecnológico. Países, comunidades ou grupos que não compartilham desse elevado grau tecnológico são considerados não somente atrasados, mas, também, um peso para os considerados desenvolvidos.

Mas qual seria o papel do conhecimento na sociedade do conhecimento? David e Foray (2003) distinguem o conhecimento da informação. O conhecimento, em qualquer área, seria aqueles saberes que empoderam o seu proprietário através da sua capacidade intelectual e física de ação. Para os autores, seria mais uma capacidade cognitiva do que, propriamente, um conhecimento. A informação, por sua vez, assume a forma de dados estruturados e formatados, necessários para interpretar e processá-los. Os custos para gerar ambos são diversos, uma vez que para gerar dados basta reproduzi-los, exigindo baixo investimento. Produzir, decodificar e reproduzir conhecimentos são processos muito mais caros e complexos.

\footnotetext{
${ }^{5}$ Tradução nossa. No original: Knowledge-based economy.
} 
Para os autores, acima de tudo, o conhecimento deveria, enquanto capital imaterial, possuir determinadas propriedades: ser aplicável, estando dessa forma associado a uma perspectiva pragmática, vinculado à noção de competências; ser permanentemente atualizado e reinventado, pois se defasa rapidamente; estar livremente disponível para fluir através das fronteiras, especialmente as favorecidas com o uso de determinadas ferramentas e dispositivos tecnológicos, tais como as networks e a internet. O crescimento da importância do conhecimento tecnológico, associado ao desenvolvimento, abriria, ainda, espaço para os empreendedores. Essas características do conhecimento se confundem com o novo perfil do capital humano da sociedade do conhecimento.

O que se pode observar é que, uma vez associado às competências aplicáveis a determinados contextos produtivos e em constante movimento, o conhecimento, propriamente dito, passa a um plano secundário e assume um papel central na habilidade de "aprender a aprender". "Aprender" seria factível de ser ensinado pelos professores e aprendido pelos estudantes. Segundo Claxton (2004), estudos recentes sobre a inteligência têm mostrado que o seu desenvolvimento não é uma simples questão de aprender novas técnicas ou o domínio de novas habilidades, tal como o "pensamento crítico". Estão mais associadas às atitudes, crenças, emoções e valores, que, por sua vez, mudam de forma lenta nos indivíduos. Necessitam de ambientes que permitam a imersão em determinada situação, com o uso da imitação, da imaginação e da intuição. $O$ conteúdo, aparentemente, deveria fluir naturalmente dessas experiências. Também, não há necessidade de guardar nada na memória do cérebro. Os bancos de dados dos hardwares já vêm fazendo isso melhor. Portanto, há no cerne da sociedade do conhecimento um discurso de desvalorização do próprio conhecimento, colocando em primeiro plano as habilidades cognitivas $e$ comportamentais que levariam à sua rápida aquisição, quando se trata de discutir que perfil de educação destinada aos trabalhadores seria o mais adequado nesse contexto. Não há qualquer discussão política sobre o seu papel social, de seu caráter ideológico ou político. Os conhecimentos são pressupostos, mas nunca evidenciados. 
Aos docentes caberia o papel de desenvolver sujeitos capazes de acompanhar esse fluxo frenético dos conhecimentos. Essa deveria ser também a prioridade no desenvolvimento de um currículo. Dessa forma, a escola e os docentes estariam preparando as novas gerações para viver na sociedade do conhecimento contemporânea e os estudantes desenvolveriam a habilidade mais preciosa de todas: a capacidade de aprender. Oportunamente, pouco se discute sobre o papel do contexto escolar, se rico ou precário, dentro do processo de ensinar a aprender $e$ as suas possibilidades de desenvolver a criatividade, $\mathrm{O}$ trabalho em grupo e a curiosidade nos estudantes. Em geral, basta oferecer cursos de atualização aos docentes nessa nova perspectiva para que aprendam a aplicar determinadas técnicas em sala de aula.

Segundo Lazaratto (2006), esse movimento de mudanças representa um processo de reestruturação do próprio trabalhador. Para o autor, toda essa grande transformação começou nos anos 70 e vem mudando o mundo do trabalho $e$ as questões que até então vinham sendo colocadas. O trabalho manual está, cada vez mais, assumindo características do trabalho intelectual, e as novas tecnologias de comunicação vêm solicitando novas subjetividades ricas em conhecimento. Uma nova massa intelectualizada está sendo produzida em uma combinação, ora em disputa de demandas da produção capitalista, ora na forma de autovalorização do trabalhador. $\mathrm{O}$ processo de trabalho não distingue mais o trabalho material $e$ o imaterial, a concepção e a execução, a autoria e a audiência, o comando e a obediência verticalizados. Porém, a grande demanda do capital é conseguir envolver a alma do trabalhador, em que sua personalidade e subjetividade devem ser suscetíveis de comando e organização, em particular, via mecanismos de controle presentes nas chamadas gestões participativas, concebidas como forma consistente de cooptação. Para Lazaratto (2006), esse novo contexto representa um terreno novo de conflitos, inclusive os gerados pelo próprio processo de participação.

No contexto dessas mudanças, os conhecimentos são assumidos num processo acelerado de defasagem. São, portanto, descartáveis. Não valeria a pena para a grande parte da população se apropriar deles, a quem serão destinados 
apenas os trabalhos que exigem poucos conhecimentos, a não ser por uma elite intelectual. O conhecimento, na sociedade do conhecimento, é para o domínio de poucos e somente esses poucos estarão em condições de assumir os poucos cargos altamente qualificados disponíveis no mundo do trabalho da sociedade do conhecimento.

Como afirma Hargreaves (2003), a sociedade do conhecimento é guiada pela criatividade e pela engenhosidade. $\mathrm{E}$, ao mesmo tempo, pelo investimento em tempo produtivo, pelo consumo, por um menor tempo para viver em comunidade, pela insegurança, pela desconfiança, mas, acima de tudo, guiada pelo lucro e pela instabilidade social provocada pela distância crescente entre ricos e pobres.

No campo educacional e, particularmente, nas políticas curriculares, o que se observa é uma constante tentativa de limitar, padronizar e mensurar os conhecimentos curriculares, que não deixaram de existir, mas perderam a sua força social e política, uma vez que estão cada vez mais reduzidos a padrões mínimos. A sociedade do conhecimento, portanto, não é apenas uma retórica ingênua. Para o trabalho docente e para o currículo, esta se transformou em uma camisa de força, que limita os movimentos e os saberes considerados relevantes em seus contextos.

\section{As implicações para o currículo $e$ as identidades}

Entendemos o currículo escolar como um lugar em que diversas narrativas são contadas, isto é, representa um lugar privilegiado que diz como o outro deve ser. O currículo escolar está intrinsecamente relacionado com os processos de subjetivação e com a socialização dirigida e controlada do sujeito. O currículo "é produtivo: ele não se movimenta apenas no campo da narrativa sobre o dever ser, ele faz", nas palavras de Costa (2001, p. 52). Em outras palavras, o currículo molda as formas de pensar, as condutas e as maneiras de ser das pessoas.

Assim, no campo das teorias curriculares, por volta dos anos de 1990, com base nos estudos de Michael Foucault e de vários estudiosos, inicia-se uma nova fase para os estudos no campo do currículo. A Teoria Pós-crítica entra em cena. O currículo, em uma perspectiva pós-crítica, questiona o conhecimento monocultural 
posto pela escola capitalista e pelo ideário moderno, e passa a ter a sua hegemonia patriarcal e branca interrogada. Como afirma Silva (2006, p. 13-14):

É o impacto das teorizações pós-modernas e pósestruturalistas tais como representadas, sobretudo pelos Estudos Culturais e sintetizadas na chamada "virada linguística", que vem modificar radicalmente essas concepções iniciais. Nas novas concepções ganha centralidade o papel da linguagem e do discurso na constituição social.

Por outro lado, Moreira (1997) mostra claramente que as categorias da Teoria Crítica não podem ser negligenciadas nos tempos atuais, mas que vários autores, ao reverem as suas principais análises, filiam-se às discussões $e$ às temáticas pós-modernas. Assim, o currículo escolar, analisado na perspectiva da teorização Pós-crítica, articula a pluralidade cultural mais ampla da sociedade com as identidades presentes na sala de aula (MOREIRA; MACEDO, 2002). Nesse sentido, indaga-se: sendo "pós", ela supera a Teoria Crítica? Pacheco (2002, p. 54) afirma que a "Teoria Pós-crítica deve combinar-se com a Teoria Crítica para ajudar-nos a compreender os processos pelos quais através das relações de poder $e$ controle nos tornamos aquilo que somos". Entendemos que a Teoria Pós-Crítica fornece outras lentes que nos ajudam a questionar a realidade. O que há é uma mistura, um deslizamento, ou, ainda, um embate travado por ambos os lados (MACEDO, 2013). Por sua vez, Silva (2002) é solicitado a responder se as teorias críticas já se esgotaram. O autor argumenta da seguinte forma:

Sim creio que há um certo esgotamento das assim chamadas teorias críticas, se por isto entendemos aquele movimento que, sob influências variadas (marxismo, sociologia crítica, freirianismo), foi responsável por uma importantíssima virada na forma de conceber e analisar a educação. Elas ainda podem ser consideradas como uma das perspectivas indispensáveis para a concepção $e$ análise da educação (GADIN; PARASKEVA; HIPOLITO, 2002, p. 8).

Nessa perspectiva, dizer que a teoria pós-crítica do currículo rompe totalmente com a teorização crítica, é entender que o conhecimento somente pode 
ser construído a partir de um único olhar. Sabemos que a produção científica é uma construção e, portanto, toma-se por base o que já se tem produzido.

Lopes (2005) deixa claro que o campo do currículo vem se caracterizando por certo hibridismo teórico. Tal hibridismo se caracteriza pela associação de princípios teóricos modernos e pós-modernos, estruturalistas e pós-estruturalistas. Dentro dessa linha de pensamento, o autor argumenta que, no âmbito internacional, há dois estudiosos célebres, Giroux e McLaren, que fazem essa associação. Em outras palavras, esses autores assumem filiações pós-estruturalistas, mas utilizam, também, categorias marxistas e freirianas. No Brasil, não tem sido diferente. Há um hibridismo de discursos críticos e pós-críticos.

Se as teorias pós-críticas são utilizadas em virtude de sua análise mais instigante da cultura, capaz de superar divisões hierárquicas, particularmente da cultura escolar, a referência à teoria crítica ainda está presente nas análises que buscam não desconsiderar, ou visam salientar, questões políticas, bem como uma agenda para mudança social (LOPES, 2005, p. 51).

No entanto, depois dos Estudos Culturais, não se concebe a categoria classe como a única forma adequada para entender a realidade e explicar a dinâmica das lutas sociais. A classe não é mais importante do que as questões culturais, a exemplo das questões de raça e etnia. Entendemos que as experiências são complexas para serem entendidas de uma única forma. Ademais, o currículo não diz respeito apenas aos conhecimentos escolares em seu sentido mais restrito, mas abrange a formação dos sujeitos e de suas identidades em diversos espaços da sociedade.

Essa compreensão sobre o currículo, no entanto, não chegou a ser formulada através das ferramentas disponibilizadas pela teoria crítica, mas através de suas inestimáveis contribuições para os avanços da teorização curricular.

Nesse caso, parece que o fenômeno mais instigante, na nossa vida, é entender como se dá a construção de nós mesmos. Compreendemos que as identidades sociais e culturais são forjadas em um processo contínuo de interação com o meio e com o outro e que o currículo não é o único responsável por essa 
construção. Apesar disso, sabemos que a educação é essencial para nos tornarmos o que somos. "Nenhuma identidade é construída no isolamento" (GOMES, 2002, p. 2), embora compreendamos, também, que nossas identidades são como mosaicos e, por isso, nunca estão prontas. A identidade é, por assim dizer, necessariamente incompleta, não fixa. A identidade não é apenas um processo de representação da pessoa, mas sim, um processo complexo de metamorfose do sujeito. Segundo Ferreira (2004), essa metamorfose acontece através da interação e da interpretação da realidade que, de certa forma, foi significativa para a pessoa. A identidade se forja, acima de tudo, nas disputas e nas relações de poder, em que está em jogo o que deve ser determinado sujeito em determinado contexto.

O reconhecimento ou não que o outro faz de nós atinge a ideia que fazemos de nós mesmos. A identidade é negociada durante toda a nossa vida, por meio de trocas e do diálogo com o outro. Ela é parcialmente exterior e parcialmente interior. É nesse sentido que, conforme sugere Gomes (2002), precisamos entender a identidade como algo construído histórica e culturalmente, repleta de vivências intensas, cheias de conflitos, lutas e jogos de poder que são, predominantemente, discursivos.

As narrativas contadas pelo outro ou por nós, na verdade, vão configurando as nossas histórias. A relação entre passado, presente e futuro se dá, justamente, nesse processo contínuo da construção dessas narrativas. Em outras palavras, as narrativas são instrumentos que utilizamos e que dão sentido ao mundo. $\mathrm{O}$ fato de contarmos e ouvirmos histórias sobre nós, sobre o outro, sobre a nossa origem, o que somos e o que fazemos tem um papel fundamental na construção das nossas vidas, dos nossos sonhos e daquilo que queremos nos tornar. Enfim, quando contamos histórias, estamos atuando sobre as outras pessoas. Conforme Lopes (2002), o fato de contarmos histórias nos fornece um autorretrato através do qual podemos descobrir/refletir as visões que temos e que o outro também tem sobre o mundo. Nesse sentido, não podemos desconsiderar as tantas narrativas que atravessam o currículo escolar, as quais os estudantes estão expostos durante anos de sua vida. 
As interpretações dos acontecimentos $e$ dos contextos não constituem apenas um traço material, mas a construção do próprio participante. Por outro lado, a narrativa contada tem o poder de dizer sobre o drama social, pois envolve autores, cenários, instrumentos e problemas. Além disso, a narrativa tem uma natureza avaliativa. Conforme o mesmo autor, fazemos julgamentos dos acontecimentos narrados e colocamos o nosso ponto de vista $e$ a nossa interpretação sobre o que é dito e não dito - o que está colocado implicitamente.

Como a identidade, de certa maneira, trama o modo de ser do sujeito, é preciso não deixar de perceber que ela pode sujeitar a pessoa a um modo social determinado ou possibilitar a autonomia e a emancipação do sujeito.

Sendo assim, na escola não aprendemos somente conteúdos, não realizamos apenas tarefas escolares ou fazemos provas. Aprendemos narrativas sobre o outro, nos deparamos com diferentes olhares sobre a cultura e a história de cada povo. A escola é uma das instâncias sociais que ajudam na construção da identidade do estudante e o faz através do currículo.

Por tudo isso, não se pode negligenciar a importância do currículo. O currículo constitui o núcleo do processo educacional e, por isso, sofre a influência dos diversos segmentos sociais, a partir das políticas que tentam traduzir as múltiplas identidades vividas pelos sujeitos no mundo contemporâneo.

Nessas discussões, pouco se diz sobre as relações de poder presentes no relacionamento entre as pessoas, pouco se descobre sobre o outro e pouco se discute as nossas relações cotidianas. Skliar (2005), apoiado em Derrida, instiganos a pensar a hostilidade da escola acerca do outro, do diferente, daquele que foge à norma, ao padrão. Para Derrida, é interessante discutir o mesmo e o outro da educação, relacionar a questão das identidades, repensar as questões sobre a ética, refletir sobre a condição dos relacionamentos entre professores e estudantes.

Como propõe Silva (2000), o currículo é uma questão de saber, poder e identidade. Apesar da aparente disjunção entre a teoria crítica e a pós-crítica, juntas elas podem ser úteis para entender a sociedade e a escola na atualidade. Portanto, o currículo pode ser compreendido como algo abrangente, complexo, multifacetado e, também, como um espaço de conflitos, de disputas, nos quais se 
entrecruzam discursos e lógicas diferentes e de difícil compreensão.

É importante afirmar que o currículo é o espaço em que se desdobram contradições, ambiguidades e conflitos, sobre os quais diferentes significados do social e do político estão presentes. É através dele que o sujeito vai se construindo. O currículo concebido como política curricular delineia concepções de ser humano e do tipo de sociedade que se quer formar.

Ao concebermos o currículo como narrativa ou discurso, que pressupõe determinadas interações sociais que envolvem, ao mesmo tempo, a produção do conhecimento e de subjetividades, uma das tarefas mais importantes é localizar nessa interação as influências do novo modelo de sociedade no seu interior e seus efeitos nas subjetividades dos sujeitos envolvidos, especialmente na linguagem presente nas novas tecnologias e nos modelos pedagógicos veiculados nas escolas, principalmente o modelo das competências e do "aprender a aprender" da sociedade do conhecimento contemporânea.

Para Gordon (1991, p. 44), o liberalismo produz um tipo de identidade do trabalhador que, massivamente, deve procurar todas as possibilidades para manter-se, permanentemente, empregado no mercado de trabalho. Essa procura incessante deve ser entendida como um empreendimento pessoal e que deve ser obtido através de seu próprio capital humano. Esse capital humano significa investir nas competências ou nessas tecnologias de si, que envolvem autoconsciência, desempenho, autorrealização e, também, autoapresentação, autoavaliação e, poderíamos acrescentar, ainda, a autoformação. "O que alguns críticos culturais diagnosticam como sendo o triunfo do narcisismo autoconsumista, talvez possa ser mais adequadamente entendido como parte de uma gestão da identidade pessoal e das relações pessoais que acompanham a capitalização do significado da vida"6 (GORDON, 1991, p. 44) [tradução nossa].

Em última análise, as competências dão uma sensação de que os indivíduos estão em pleno controle da situação, tanto no trabalho, quanto nas suas vidas pessoais, e que estão assumindo a responsabilidade de suas ações, sejam elas bem

\footnotetext{
6 "What some cultural critics diagnose as the triumph of auto-consuming narcissism can perhaps be more adequately understood as part of the managerialization of personal identity and personal relations which accompanies the capitalization of the meaning of life". (No original).
} 
sucedidas ou não. $\mathrm{O}$ aprender a aprender pretende incutir a mesma sensação de autonomia e poder sobre os sujeitos no que se refere ao seu percurso formativo. As tecnologias em si mudam a autoimagem que os indivíduos têm de si mesmos e da realidade. Mais precisamente, criam a si mesmos, suas identidades, dentro desse sistema de regras e técnicas que passam a ser suas, moldando os seus desejos e interesses.

Os efeitos do currículo centrado nas competências sobre os indivíduos são ambíguos, uma vez que podem ser produtivos ou repressivos. Com efeito, essa tecnologia não têm somente efeitos limitadores ou constrangedores sobre as atitudes e o desempenho dos trabalhadores, direcionando-os para práticas de exploração e subjetivação; elas podem, também, ser produtivas ou positivas, na medida em que podem, também, auxiliar as pessoas a perceberem que possuem habilidades, que poderiam ser subestimadas ou mesmo negligenciadas. McKinlay e Starkey (1998) afirmam que, junto aos dispositivos de controle instituídos, coexiste uma variedade de códigos, discursos e práticas que refletem os desejos dos vários grupos que constituem determinadas organizações.

Para Lazaratto (2006), as novas formas de ser e conhecer demandam novas tecnologias e as novas tecnologias demandam novas formas de ser e conhecer. Esse processo cria um novo ambiente social, cultural, econômico e educacional, na tentativa de transformar a criatividade e os valores humanos, guiando-os para uma determinada direção que alimente e mantenha legítimo o sistema produtivo como tal, ou seja, como produtor de consumidores e trabalhadores capazes de produzir lucro em determinadas condições produtivas.

Nesse modelo de racionalidade, o conhecimento curricular é jogado, paradoxalmente, a um papel secundário, passando para o centro dos processos educacionais a didática orientada pelas competências. Ao assumir que os saberes envelhecem precocemente, é inútil que os sujeitos se envolvam em processos de aprendizagem de conteúdos. As reformas curriculares iniciadas nos anos de 1990 no Brasil são, notadamente, influenciadas pela pedagogia construtivista, com ênfase no autocontrole, na autonomia, na criatividade, na desinibição, na capacidade de análise, na comunicação oral e no bom desempenho em grupo. 
Para Ball (2013, p. 152), os sujeitos privilegiados nesse processo são pertencentes à classe média liberal, "com recursos sociais, culturais, emocionais $e$ financeiros disponíveis, com um estilo de vida particular e com certo repertório de comprometimentos. A inabilidade para lidar com a presença das incertezas $e$ instabilidades é suscetível de receber intervenções corretivas". Ou seja, os beneficiados por essa retórica são os que já estavam em condições privilegiadas e estáveis na sociedade e enfrentarão a instabilidade, a fluidez e o esvaziamento dos currículos escolares, com maior probabilidade de sucesso, ao ingressarem na universidade e no mercado de trabalho. A classe média sempre foi capaz de dispor de vários meios, além do escolar, para aprimorar as chances de sucesso de seus filhos no mundo do trabalho, bem como de oferecer suporte para as incertezas e os momentos difíceis que porventura possam vir e cada vez mais as famílias se empenham em oferecer cursos paralelos ao sistema formal de ensino como complemento à sua formação.

Nesse processo, é difícil perceber em que se ancoram as competências, uma vez que não se aprende algo. A única coisa que merece ser aprendida é ser algo: empregável (BALL, 2013). Ao mesmo tempo, ao assumirem o conhecimento como descartável e com validade vencida, as competências resultantes desse modelo tendem a ser cada vez mais superficiais, voláteis e frágeis.

\section{A prática docente e o currículo na sociedade do conhecimento: para além do governo da aprendizagem}

A sociedade do conhecimento não é apenas uma retórica. Ela envolve instituições, sujeitos, tecnologias, mídias, saberes e relações sociais muito definidas. Em certo nível, envolve um estágio de avanço tecnológico que não é mais possível imaginar viver sem, como a internet, o computador e o celular, para citar alguns exemplos arraigados no cotidiano de grande parte das pessoas. Todas as esferas da vida dos sujeitos estão sendo incorporadas no discurso das competências e da aprendizagem: comer, vestir, o tempo livre, a sexualidade e as emoções são suscetíveis à aprendizagem. Também, os sujeitos devem fazer parte de uma espécie 
de autogestão que todos devem aprender para ter sucesso, tanto na vida pessoal e social, quanto profissional, e preferencialmente, circulando em redes sociais ou de promoção pessoal, tais como o Facebook, o LinkedIn, dentre outros.

Segundo Simons e Masschelein (2008), a palavra aprendizagem está se tornando indispensável para pensar sobre nós mesmos e sobre os outros. Assim como no mundo do trabalho, para a democracia funcionar, por exemplo, certas competências também precisam ser aprendidas. Portanto, aprender está se tornando um assunto que diz respeito ao governamento e ao autogovernamento, algo que pode ser administrado em benefício próprio, avaliado e, acima de tudo, transformado em uma forma de adicionar valor a si mesmo e ao capital, em termos produtivos, em uma espécie de versão pós-industrial da Teoria do Capital Humano. Qualquer fracasso nessa intenção pode ser entendido como uma falha pessoal, por não conseguir administrar o seu próprio percurso de aprendizagem de forma adequada, ou por falta de visão das possibilidades, por falta de adaptação, por imaturidade ou mesmo por irresponsabilidade.

Mas que papel cabe aos educadores, nesse contexto? Seria o de incutir nos estudantes não tanto a "vontade de saber", mas a "vontade de aprender" para estar, permanentemente, aprendendo novos $e$ úteis conhecimentos por toda a vida. E a forma de fazê-lo é inovando a sua didática por meio do modelo das competências que, como vimos, pretende formar um sujeito apto para estar permanentemente empregável em um mundo de constante mudança. A sua subjetividade é o foco principal do processo educacional.

Entretanto, é importante destacar que os docentes também estão sob uma forte pressão para manterem-se em constante aprendizado, como forma de estarem atualizados e profissionalizados. Desde o início das reformas educacionais nos anos 90, há uma grande mobilização em torno da reciclagem dos professores e parece haver um consenso na opinião pública $e$ nas iniciativas governamentais de que o sucesso da educação reside na formação docente. No entanto, ao focar sobre a formação docente, tendem a não ser prioridade na agenda governamental fatores outros que promovam melhores condições de trabalho e de salários. 
O paradoxo diante dessa realidade é que, mesmo diante das inúmeras dificuldades que surgem devido à precariedade do trabalho docente no Brasil já amplamente discutida, cabe mais uma vez a cada docente ressignificar a sua própria prática. E uma pergunta permanece: Qual o sentido da educação que estamos oferecendo a nossos educandos? Entendemos que, por mais ambígua que seja a nossa prática, ela deve ser pensada como um lócus de pesquisa, isto é, de produção de conhecimento, para ajudar na formação de pessoas que não apenas se adaptem ao mundo em que vivemos, e sim, de pessoas que sejam capazes de pensar e construir outro tipo de sociedade, que valorize o convívio ético, democrático e justo entre os sujeitos.

Nas palavras de Veiga (2012, p. 59), "a idéia do ensino articulado à pesquisa está baseada em atitudes analíticas, reflexivas, questionadoras e problematizadoras". Assim, a aprendizagem parte das indagações realizadas pelos docentes e pelos estudantes. Além do mais, o nosso papel é, enquanto mediador do conhecimento, ensinar os educandos a pesquisar. Para isso, o educador precisa explicar o que é pesquisa: o significado para a nossa vida e os seus diversos tipos. A partir dessas discussões, objetiva-se levar os estudantes a refletirem que pesquisa não é sinônimo de cópia, mas sim, um momento de produção, autoria, reflexão e, consequentemente, construção de novos pensamentos que postulem novos ideais, baseados em saberes que preexistiam.

Aprender não significa simplesmente armazenamento de informações para transmitir aos colegas, professores, dentre outras pessoas, ou provar que sabe nas avaliações. Não significa desenvolver habilidades cognitivas meramente instrumentais. Aprender com significado implica saber selecionar as informações, organizar as ideias, incorporar as novas modalidades de concepção de mundo $e$ produzir conhecimento, fazendo uma relação entre a teoria e a prática. Enfim, ao pesquisar o que se ensina, temos o prazer da descoberta, desenvolvemos a criatividade de forma crítica e criamos novos conhecimentos. O mais importante de tudo isso é romper com os padrões estabelecidos pela sociedade em que vivemos.

\section{Considerações Finais}


Repensar a nossa prática docente é sempre uma possibilidade de crescimento pessoal, apesar das dificuldades que vivemos enquanto profissionais da educação, seja no ensino superior ou na educação básica. O ritmo acelerado de trabalho $e$ as condições materiais inadequadas são entraves no cotidiano das nossas ações, o que nos leva a lutar coletivamente por melhorias. Concomitantemente à luta política, temos que travar outros embates, talvez, mais intensos, pois dizem respeito às mudanças dos sujeitos, tanto como seres humanos quanto como profissionais. A prática docente é um processo aberto às vivências diversas. Sendo assim, vamos a todo tempo ensinar e aprender. Nas palavras de Freire (2011, p. 35), "não há seres educados e não educados. Estamos todos nos educando. Existem graus de educação, mas estes não são absolutos".

A sala de aula é sempre um espaço de aprendizado e de sentido diversos. Nessa perspectiva, seria um tecido, um arranjo com muitos fios de heterogêneas texturas entrelaçados por muitas camadas de leituras (LOPES; CUNHA; COSTA, 2013). A partir do campo do currículo, entendemos que o nosso trabalho não é neutro e que o processo didático é um movimento complexo que envolve, pelo menos, quatro dimensões: "ensinar, aprender de forma significativa, pesquisar $e$ avaliar”, conforme salienta Veiga (2012, p. 53). Essas dimensões são intercaladas nas quais fatores históricos, culturais, políticos, coletivos e individuais se misturam.

Ensinar e aprender são processos que envolvem não apenas mostrar os possíveis caminhos, mas orientar os educandos a serem críticos, para que possam ler o mundo e traçar possibilidades de mudanças. Também, intuí-los a ter posições políticas claras, que possam desconstruir a retórica das competências - tão presente no contexto da sociedade do conhecimento -, sobre o discurso que pretende formar sujeitos de forma superficial e despolitizada, entregues à própria sorte, para viverem em um mundo cada vez mais competitivo, individualista, inseguro e com profundas desigualdades sociais, econômicas e culturais.

O processo de tradução exige dos docentes, portanto, doses de criatividade, criticidade e pesquisa, estabelecendo sempre uma relação da teoria com a prática, problematizando o seu tempo e o seu cotidiano. A constatação dessa realidade nos 
propicia o levantamento de alguns questionamentos, a saber: $\mathrm{O}$ que dizem as teorias? O que pensar e fazer, a partir da realidade que temos? Quais são as possibilidades e os limites? A necessidade dessas problematizações ratifica o entendimento de que na docência não há receitas prontas, haja vista que os docentes, os discentes, os espaços, as diversas culturas e a relação com o mundo é que vão dar o tom e o caminho a trilhar.

Enfim, o currículo, no seu sentido mais amplo e complexo, não é um mero processo de armazenamento de informações ou de desenvolvimento de competências, mas sim, um espaço de disputa e de construção constante dos sentidos e das práticas sociais. Nada pode ser mais profundamente político do que isso.

\section{Referências}

AMORIM, Roseane M. de. As implicações dos parâmetros curriculares nacionais para a prática pedagógica dos professores de História do ensino fundamental da rede municipal do Jaboatão dos Guararapes. Recife: UFPE, 2004. Dissertação (Mestrado em Educação). Programa de Pós-Graduação em Educação. Universidade Federal de Pernambuco, 2004.

As práticas curriculares cotidianas: um estudo da educação das relações étnico-raciais na Rede Municipal de Ensino do Recife. Recife: UFPE, 2001. Tese ( (Doutorado em Educação). Programa de Pós-Graduação em Educação. Universidade Federal de Pernambuco, 2011.

APPLE, Michael. Educação e poder. Porto Alegre: Artes Médicas, 1989.

BALL, Stephen. Sociedade ao longo da vida, subjetividade e a sociedade totalmente pedagogizada. Educação, v. 36, n. 2, p. 144-155, 2013.

CLAXTON, Guy. Learning is learnable (and we ought to teach it). In: CASSELL, J. (Ed.). Ten years on. Brighton: National commission for Education, 2004.

COSTA, Marisa V. Currículo e política cultural. In: COSTA, M. V. (Org.). O currículo nos limiares do contemporâneo. Rio de Janeiro: DP\&A, 2001.

COSTA, Thais. A noção de competência enquanto princípio de organização curricular. Revista Brasileira de Educação. N. 29, Maio/Ago, 2005.

DAVID, P. A.; FORAY, D. Economic fundamentals of the knowledge society. Policy Futures in Education - An e-Journal, v. 1, n. 1, p. 1-22, Special Issue: Education and the Knowledge Economy, 2003.

FOUCAULT, Michel. A ordem do discurso. São Paulo: Loyola, 1996. 
FREIRE, Paulo. Pedagogia do oprimido. 40. ed. Rio de Janeiro: Paz e Terra, 2005. . Educação e mudança. São Paulo: Paz e Terra, 2011.

FERREIRA, Ricardo F. Afrodescendente: identidade em construção. Rio de Janeiro/São Paulo: PALLAS, 2004.

GANDIN, Luís A.; PARASKEVA, João M.; HIPOLYTO, Álvaro M. Mapeando a [complexa] produção teórica educacional - Entrevista com Tomaz Tadeu da Silva. Currículo sem Fronteiras, v. 2, n. 1, p. 5-14, 2002.

GARCIA, Maria Manuela A. Políticas educacionais contemporâneas: tecnologias, imaginários e regimes éticos. Revista Brasileira de Educação. V. 15, n. 45, set./dez. 2010.

GOMES, Romeu. Análise dos dados na pesquisa qualitativa. In: MINAYO, M. C. de S. (Org.). Pesquisa social: teoria, método e criatividade. Petrópolis: Vozes, 2002.

GORDON, Colin. Governmental rationality: An introduction. In: BURCHELL, G.; GORDON, C. The Foucault effect. Chicago: University of Chicago Press, 1991.

GUIMARÃES, Edilene. Política do ensino médio e educação profissional: discursos pedagógicos e práticas curriculares. Recife: UFPE, 2007. Tese (Doutorado em Educação) - Programa de Pós-Graduação em Educação, Universidade Federal de Pernambuco, 2007.

HARGREAVES, A. Teaching in the knowledge society: Education in the age of insecurity. New York: Teachers' College Press, 2003.

LIBÂNEO, José C. Ensinar e aprender, aprender e ensinar: O lugar da teoria e da prática em didática. In: LIBÂNEO, J. C.; ALVES, N. (Orgs.). Temas de pedagogia: diálogo entre didática e currículo. São Paulo: Cortez, 2012.

LAZZARATO, M. Immaterial labor. In: VIRNO, P.; HARDT, M. (Eds.). Radical thought in Italy: a potential politics. Minnesota: University of Minnesota Press, 2006.

LOPES, Alice C. Política de currículo: recontextualização e hibridismo. Currículo sem Fronteiras, v. 5, n. 2, p. 50-64, 2005.

LOPES, Alice C.; CUNHA, Erika V. R. da; COSTA, Hugo H. C. Da recontextualização à tradução: investigando políticas do currículo. Currículo sem Fronteiras, v. 13, n. 3, p. 392-410, 2013.

MACEDO, Elizabeth. A noção de crise e a legitimação de discursos curriculares. Currículo sem Fronteiras, v. 13, n. 3, p. 436-450, 2013.

McKINLAY, Alan; STARKEY, Ken. Foucault, management and organization theory: from panopticon to technologies of self. London: Sage, 1998.

MOREIRA, Antônio F. B.; MACEDO, Elizabeth F. de. Currículo, identidade e diferença. In: MOREIRA, A. F.; MACEDO, E. F. de (Orgs.). Currículos, práticas pedagógicas e identidades. Portugal: Porto Editora, 2002. 
NOGUEIRA, Claudio M. M.; NOGUEIRA, Maria A. A sociologia da educação de Pierre Bourdieu: limites e contribuições. Educação e Sociedade, v. 23, n.78, p. 1536, 2002.

PACHECO, José A. Escritos curriculares. São Paulo: Cortez, 2005.

ROSE, Nikolas. Como se deve fazer a história do eu? Educação \& Realidade. N. 26 (1), Jan./Jul., 2001.

SANTIAGO, Maria E. Projeto pedagógico da escola: uma contribuição ao planejamento escolar. Revista de Administração Educacional, v. 1, n. 1, p. 69-71, 1997.

SANTOS, Lucíola L. de C. P. Bernstein e campo educacional: relevância, influências e incompreensões. Cadernos de Pesquisa, n. 120, p. 15-49, 2003.

SKLIAR, Carlos. A escrita na escrita: Derrida e a Educação. In: SKLIAR, Carlos (Org). Derrida \& a educação. Belo Horizonte: Autêntica, 2005.

SILVA, Tomaz T. da. Documentos de identidades: uma introdução às teorias críticas. Belo Horizonte: Autêntica, 2002.

O currículo como fetiche: a poética e a política do texto curricular. Belo Horizonte: Autêntica, 2006.

Identidades terminais: as transformações na política da pedagogia e na pedagogia da política. Petrópolis: Vozes, 1996. 2000.

Teorias do currículo: uma introdução crítica. Portugal: Porto Editora LDA,

SIMONS, M.; MASSCHELEIN, J. Our 'will to learn' and the assemblage of a learning apparatus. In: FEJES, A.; NICOLL, K. (Eds.). Foucault and lifelong learning: Governing the subject. New York: Routledge, 2008, p. 48-60.

VEIGA, Ilma P. A. A aventura de formar professores. São Paulo: Papirus, 2012.

Recebido em 27/07/2014

Aprovado em 01/12/2014 